\title{
Commentary: Paravalvular leaks in valve replacement: Do we need to blow the whistle?
}

\author{
Torsten Doenst, MD, PhD, and Markus Richter, MD
}

\footnotetext{
From the Department of Cardiothoracic Surgery, Jena University Hospital, Friedrich-Schiller-University of Jena, Jena, Germany.

Disclosures: Authors have nothing to disclose with regard to commercial support.

Received for publication Aug 24, 2018; accepted for publication Aug 24, 2018; available ahead of print Sept 28 , 2018.

Address for reprints: Torsten Doenst, MD, PhD, Department of Cardiothoracic Surgery, Friedrich-SchillerUniversity of Jena, Am Klinikum 1, 07747 Jena, Germany (E-mail: doenst@med.uni-jena.de).

J Thorac Cardiovasc Surg 2019;157:1793-4

$0022-5223 / \$ 36.00$

Copyright (C) 2018 by The American Association for Thoracic Surgery

https://doi.org/10.1016/j.jtcvs.2018.08.052
}

Classically, the diagnosis of a paravalvular leak (PVL) has made the surgeon feel uncomfortable, because it either reflects a technical blemish of surgical craftsmanship or signals a serious underlying pathology (eg, endocarditis or annular remodeling). Possibly as a consequence of the perceived surgical failure, the number of surgical publications on prognosis and management of paravalvular leaks is limited. ${ }^{1}$ It is well documented, however, that PVL increases risks for endocarditis and hemolytic anemia and, if severe, compromises hemodynamics.

With the advent of catheter valve technology, the perception of PVL has changed. Initially, PVL was considered a major obstacle to transcatheter aortic valve implantation (TAVI), because severe PVL was frequent and poor survival was confirmed repeatedly., Technical progress has decreased the incidence of PVL, however, and most recent studies have found mild PVL to be harmless. 3,5 PVL thus does not seem to pose a considerable problem for the expansion of TAVI into patients at lower and lower risk undergoing aortic valve replacement. ${ }^{6}$

In this issue of the Journal, Shah and colleauges ${ }^{7}$ present a large experience of purely surgical patients presenting with paravalvular leaks. They focused their analysis on patients who had an acceptable operative risk range and who were either conservatively or surgically treated (interventional techniques were reserved for patients with prohibitive surgical risk). Of almost 500 patients, the center decided to operate on two-thirds. In this surgical group, they found that despite excellent perioperative results, long-term mortality was high. They identified classic surgical risk factors as independent predictors of death, (ie, high Society of Thoracic Surgeons score, pulmonary hypertension, and endocarditis). They also found mitral leaks to be worse than aortic leaks. Shah and colleauges ${ }^{7}$ thus confirmed the TAVI literature, in which significant PVL has been found to affect survival negatively.

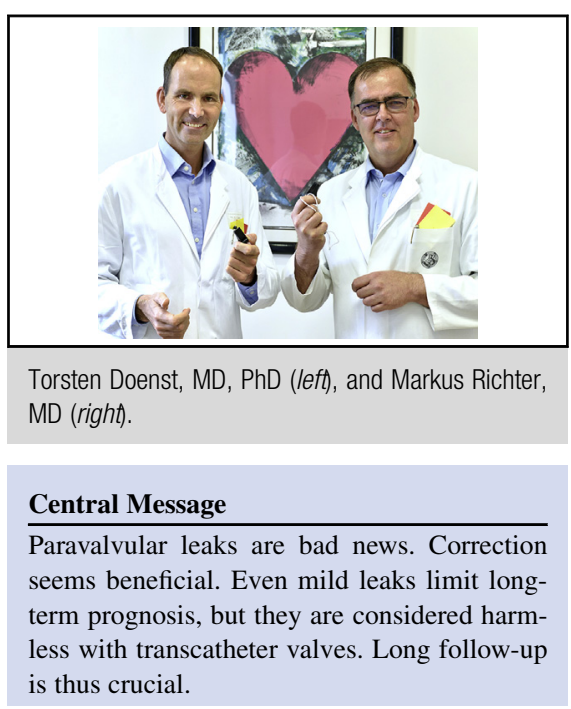

See Article page 1785 .
The decision making of Shah and colleauges ${ }^{7}$ left onethird of patients without operative intervention. Similar to the TAVI literature, PVL was mostly mild (65\%, 35\% moderate), and there was no evidence for hemolysis. Demographic data were otherwise equivalent to those of the surgical group. Surprisingly, despite the less complex PVL pattern in the conservative group, there was a significant $(>10 \%)$ worse survival probability at 12 years relative to surgical patients. Importantly, because surgery is always associated with a "mortality investment," it takes time to "harvest the benefit." When inspecting the patient survival of Shah and colleauges, ${ }^{7}$ the curves can be seen to cross, and the benefit of surgery only begins to develop at 2 to 3 years. Because most current TAVI trials have end points defined between 1 and 5 years (PARTNER 3, NCT02675114; DEDICATE, NCT03112980), it is well possible that we miss long-term negative impacts, such as that of only mild PVL, as suggested by Shah and colleagues ${ }^{7}$ here. Similar mechanisms may apply to long-term sequelae of other end points, such as new pacemakers or valve durability. ${ }^{8}$ It thus may be time to blow the whistle on our current evaluation of new valve technology-not to condemn transcatheter technology, but to emphasize the need for longer follow-up in cardiovascular trials including a surgical arm. Shah and colleagues ${ }^{7}$ present a great base for a randomized trial assessing PVL with their important article. Let us see whether our next steps can be longer. 


\section{References}

1. Kliger C, Eiros R, Isasti G, Einhorn B, Jelnin V, Cohen H, et al. Review of surgical prosthetic paravalvular leaks: diagnosis and catheter-based closure. Eur Heart J. 2013;34:638-49.

2. Dávila-Román VG, Waggoner AD, Kennard ED, Holubkov R, Jamieson WR, Englberger L, et al. Artificial valve endocarditis reduction trial echocardiography study. Prevalence and severity of paravalvular regurgitation in the artificial valve endocarditis reduction trial (AVERT) echocardiography study. J Am Coll Cardiol. 2004; $44: 1467-72$.

3. Athappan G, Patvardhan E, Tuzcu EM, Svensson LG, Lemos PA, Fraccaro C, et al. Incidence, predictors, and outcomes of aortic regurgitation after transcatheter aortic valve replacement: meta-analysis and systematic review of literature. $J$ Am Coll Cardiol. 2013;61:1585-95.

4. Kodali SK, Williams MR, Smith CR, Svensson LG, Webb JG, Makkar RR, et al; PARTNER Trial Investigators. Two-year outcomes after transcatheter or surgical aortic-valve replacement. N Engl J Med. 2012; 366:1686-95.

5. Vasa-Nicotera M, Sinning JM, Chin D, Lim TK, Spyt T, Jilaihawi H, et al. Impact of paravalvular leakage on outcome in patients after transcatheter aortic valve implantation. JACC Cardiovasc Interv. 2012;5: 858-65.

6. Khan SU, Lone AN, Saleem MA, Kaluski E. Transcatheter vs surgical aortic-valve replacement in low- to intermediate-surgical-risk candidates: a meta-analysis and systematic review. Clin Cardiol. 2017;40:974-81.

7. Shah S, Alashi A, Pettersson GB, Rodriguez LL, Gillinov AM, Grimm RA, et al. Characteristics and longer-term outcomes of paravalvular leak after aortic and mitral valve surgery. J Thorac Cardiovasc Surg. 2019;157:1785-92.e1.

8. De Biase C, Mastrokostopoulos A, Philippart R, Bonfils L, Berthoumieu P, Dumonteil N. What are the remaining limitations of TAVI? J Cardiovasc Surg (Torino). 2018;59:373-80. 